\title{
Pharmacologic prophylaxis for atrial fibrillation following cardiac surgery: a systematic review
}

\author{
Ioanna Koniari*, Efstratios Apostolakis, Christina Rogkakou, Nikolaos G Baikoussis, Dimitrios Dougenis
}

\begin{abstract}
Atrial Fibrillation (AF) is the most common arrhythmia occurring after cardiac surgery. Its incidence varies depending on type of surgery. Postoperative AF may cause hemodynamic deterioration, predispose to stroke and increase mortality. Effective treatment for prophylaxis of postoperative AF is vital as reduces hospitalization and overall morbidity. Beta - blockers, have been proved to prevent effectively atrial fibrillation following cardiac surgery and should be routinely used if there are no contraindications. Sotalol may be more effective than standard b-blockers for the prevention of AF without causing an excess of side effects. Amiodarone is useful when beta-blocker therapy is not possible or as additional prophylaxis in high risk patients. Other agents such as magnesium, calcium channels blocker or non-antiarrhythmic drugs as glycose-insulin - potassium, non-steroidal anti-inflammatory drugs, corticosteroids, $\mathrm{N}$-acetylcysteine and statins have been studied as alternative treatment for postoperative AF prophylaxis.
\end{abstract}

\section{Introduction}

Atrial Fibrillation (AF) is the most common arrhythmia occurring after cardiac surgery and its peak incidence is between second or third postoperative day. Postoperative AF ranges depending on surgery type. Especially, AF occurs in nearly $30 \%$ of patients undergoing coronary bypass grafting (CABG), and in $40 \%$ and $50 \%$ of patients after valve surgery alone or combined valve and CABG surgery respectively $[1,2]$. Pathophysiologic parameters such as the abnormal electrophysiological state of the atria, the unequal shortening of the atrial myocytes refractory period as well as variable conduction speed through the atrial tissue predispose to the development of AF. It is also considered that ischemia of the atrial tissue, increased sympathetic activation, and exaggerated inflammatory response may play a triggering role in the development of postoperative AF [3]. Risk factors of postsurgical AF could be divided into: preoperative, intra-operative and postoperative. Preoperative factors mainly include: a. atrial tissue damages due to age, previous rheumatic fever, elevated left ventricular diastolic pressure, hypertension and coronary syndromes [4-9], b. heart diseases such as left ventricular hypertrophy, left atrium enlargement or history of congestive

\footnotetext{
*Correspondence: iokoniari@yahoo.gr

Cardiothoracic Surgery Department. Patras University, School of Medicine. Rion Patras, Greece
}

heart failure $[4,10]$, and c.electrolytic imbalance such as hypokalemia, hypomagnesemia, hypothyroidism, preoperative use of digoxin or milrinone $[4,11]$. Finally, obesity, male gender, chronic obstructive pulmonary disease (COPD), tachycardia, prolonged P-wave deviation may also predispose to AF [10,12-19]. While, intra-operative risk factors could be attributed to increased sympathetic activation due to stimulation of catecholamines, reflex sympathetic activation from volume loss, anemia, pain, adrenergic drug administration, aortic cross clumping duration, early return of atrial electrical activity after cardioplegia, bicaval venous cannulation, left ventricular venting via pulmonary vein as well as extracorporeal circulation $[4,6,14,18]$. Postoperative AF may be correlated with hemodynamic deterioration (myocardial infarction, heart failure, thromboembolism, bleeding due to anticoagulation), stroke, hypomagnesemia [15], extubation time [16], and others as increase in postoperative Pwave dispersion [17] and exaggerated inflammation reaction [18-21]. Consequently, the effective treatment for the prevention of postoperative AF is of vital importance. Numerous pharmacologic strategies attempt to reduce the incidence of postoperative AF. Overall, most reported studies demonstrate a positive effect with a variety of pharmacologic agents either anti-arrhythmic ( $\beta$-blocker, amiodarone, magnesium, calcium blocker) or non-antiarrhythmic drugs (glycose-insulin-potassium, 
non-steroidal anti-inflammatory drugs, corticosteroids, $\mathrm{N}$-acetylcysteine, statins); to date, however, no signal particular agent or combination of agent have completely eliminated post cardiac surgery AF.

\section{Pharmacologic prophylaxis for postoperative atrial fibrillation}

Beta-blockers

All identified meta-analyses demonstrated that b-blockers significantly reduced the incidence of postoperative AF [9-13]. Particularly, Andrews et al, showed that the incidence of post-CABG AF decreased from $34 \%$ to 8 , $7 \%$ in patients received b-blockers. In another meta-analysis of Kowey et al, the decrease in incidence of AF was from $20 \%$ to $8,7 \%$ [22]. However, Crystal et al performed the largest meta-analysis based on 27 randomised controlled trials that included 3.840 patients. Especially, the control group presented an incidence of AF approximately $33 \%$, while notably patients receiving b-blockers had an incidence of 19\% [23]. Ferguson et al [24], in another large retrospective analysis of the Thoracic Surgeons surgical database that included 629.877 patients, observed the morbidity and mortality rate associated with the peri-operative use of b-blockers. Notably, they revealed a reduction in mortality rate from $3.4 \%$ to $2.8 \%$ in patients that received peri-operatively b-blockers. Numerous randomized trials have been conducted so as to evaluate the effectiveness of b-blockers in the prevention of AF. In b-Blocker Length of Stay (BLOS) trial, Connolly et al, evaluated the efficacy of metoprolol against placebo therapy in preventing postoperative AF in 1000 patients undergoing cardiac surgery [25]. In all, $85 \%$ of patients had CABG surgery and the remainder had valve surgery or combined valve and CABG surgery. The administered daily dose of metoprolol was 100 or $150 \mathrm{mg}$ starting immediately after the surgery and continued until discharge from the hospital. The incidence of postoperative AF was significantly lower in metoprolol group (31\%) compared to placebo (39\%), representing a relative risk reduction of $20 \%$.

Similarly, Lucio et al, randomized 200 patients underwent isolated CABG to receive either metoprolol or no drug [26]. Metoprolol was given orally adjusted to maintain optimal heart rate and started from the 12th hour to the 7 th postoperative day or hospital discharge. Postoperative AF and flutter occurred at $24 \%$ in control versus $11 \%$ in metoprolol group $(\mathrm{p}=0.02)$. Tsuboi et al, randomized 160 patients who underwent scheduled isolated CABG to receive either carvedilol or not [27]. Postoperative paroxysmal AF was $15 \%$ in carvedilol group ( $\mathrm{p}=0.009$ ). White et al, assigned randomly 41 patients after CABG to receive prophylactic timolol or placebo. Timolol $0.5 \mathrm{mg}$ diluted in $10 \mathrm{ml}$ of saline was given IV over 1 min twice daily only when patient condition was stable, following oral timolol twice daily for 7 days. Timolol decreased significantly $(p<0.05)$ the episodes of supraventricular tachycardia as well as of AF and/or flutter [28]. Lamb et al, randomized 60 patients underwent CABG treated with atenolol or not. Remarkably, $37 \%$ of patients in control group experienced a sypraventricular arrhythmia compared to $3 \%$ in atenolol group ( $p=0.001$ ) [29]. Several studies compared the efficacy of iv or oral b-blocker as well as different types of b-blocker. Halonen et al, in an attempt to compare the iv with the oral use of metoprolol, randomized 240 patients who underwent first on pump CABG, aortic valve replacement or combined aortic valve replacement and CABG [30]. In both groups, the metoprolol administration was based on heart rate for a 48 hour period. Postoperative AF presented a significant decrease ( $\mathrm{p}=$ $0.036)$ in IV group (16.8\%) compared to oral group (28.1\%). It should be mentioned that patients at risk to develop complications associated with IV metoprolol were excluded. Also, Maniar et al randomized 47 patients for elective CABG to receive either esmolol IV or standard oral $\beta$-blocker (propanolol/metoprolol) [31]. Esmolol was given within 6 to 18 hours of arrival to recovery room, continued for up to 24 hours and then these patients transitioned to oral $\beta$-blocker. The incidence of postoperative AF was the same (26\%) in both groups. However, patients in esmolol group developed significant adverse effects (hypotension, symptomatic bradycardia, CHF) compared to oral $\beta$-blocker. An important limitation was that patients in oral $\beta$-blocker group received greater number of bypass grafts than in the esmolol group. Similarly, Balcetyte - Harris et al [32], showed that the tolerance to esmolol was poor, and that its effectiveness in the prevention of atrial fibrillation was not better than oral b-blockers.

Moreover, comparison of the effectiveness between metoprolol and carvedilol has also been performed. Especially, Acikel et al [33], randomized 110 patients scheduled for elective CABG to receive either metoprolol $(50 \mathrm{mg} \mathrm{td})$ or carvedilol $(12,5 \mathrm{mg} \mathrm{td})$. Therapy was started 3 days prior to surgery and continued in the postoperative period with mean dosages of carvedilol (13 mg daily) and metorpolol (58 mg/day) in corresponding groups. Postoperative AF had an incidence of $36.4 \%$ in metorpolol compared to $16 \%$ in carvedilol group ( $\mathrm{p}=0.029$ ). Also, Hafgjoo et al [34], randomized 120 patients underwent $\mathrm{CABG}$ to receive metoprolol or carvedilol. In this study, the therapy was started 10 days prior the surgery and initiated with an oral dose of carvedilol $6.25 \mathrm{mg}$ and $25 \mathrm{mg}$ metoprolol twice daily respectively. Then the dosage was increased until the maximum tolerated dose. The incidence of postoperative AF was significantly reduced $(\mathrm{p}=0.022)$ in carvedilol (15\%) compared with metoprolol (33\%) group. However, 
the study presented several limitations: it was a single centre study consisted of small number of patients and thus, inflammation markers such as CRP had not been measured, despite the hypothesis that anti-inflammatory properties of carvedilol may have contributed to increased efficacy. Finally, several studies compared atenolol with other regiments such as digitalis or propafenone. Yazicioglu et al [35], randomized 160 patients underwent CABG into 4 groups of treatment: a. digoxin and atenolol, b. digoxin, c. atenolol, d. placebo. The combination of atenolol and digitalis (5\%) decreased significantly postoperative AF compared with placebo $(25 \%, p=0.012)$ but there was no significant difference compared to digoxin or atenolol alone $(17.9 \%, 15.4 \% \mathrm{p}=$ 0.087). Merrick et al [36], in SPPAF trial allocated randomly 207 patients underwent non-emergency cardiac surgery, to receive orally either propafenone $300 \mathrm{mg}$ twice daily or atenolol $50 \mathrm{mg}$ once daily from the first until the 7th postoperative day or until an end point (AF appearance) was reached. The atenolol and the propafenone presented equal efficacy $(10,7 \%$ vs. $12 \%)$ in the prevention of AF.

\section{Sotalol}

Sotalol is a b-blocker that also disposes Class III antiarrhythmic characteristics. The effectiveness of sotalol has been proved in placebo control trials $[37,38]$. Pfisterer et al [37], randomized 255 patients, who referred for CABG or aortic valve operation, to receive either 80 $\mathrm{mg}$ of sotalol orally or matching placebo. Sotalol reduced significantly $(\mathrm{p}=0.0012)$ the rate of postoperative sypraventricular tachy-arrhythmia from $46 \%$ (placebo) to $26 \%$ as well as the length of hospital stay ( $\mathrm{p}<$ $0.05)$. Preoperative $\beta$-blockers therapy was stopped before the surgery, fact that might have been responsible for increasing incidence of SVA arrhythmia in placebo group. Gomes et al, randomized 130 patients underwent open heart surgery, to receive sotalol ( $80 \mathrm{mg}$ to $120 \mathrm{mg}$ ) or placebo [38]. Sotalol significantly decreased ( $\mathrm{p}<$ $0.001)$ postoperative AF (12.5\%) compared to placebo (38\%). An important limitation was the low number of participants. Several randomized controlled trials compared sotalol to conventional b-blockers. The largest study was by Suttorp et al $[39,40]$, who performed a four-arm study comparing low or high doses of sotalol or propranolol in 429 patients. Sotalol $40 \mathrm{mg}$ tds resulted in an incidence of $14 \%$ of AF compared with $19 \%$ incidence of low dose propranolol, revealing no statistical significance. Auer et al [41] randomized 312 patients underwent cardiac surgery into four groups: 1 . metoprolol in combination with oral amiodarone, 2. metoprolol, 3. Sotalol, 4. placebo. The incidence of AF was $32 \%$ with sotalol and $40 \%$ with metoprolol, although this was again non-significant. Combined metoprolol and amiodarone as well as sotalol had a significant lower frequence of AF than placebo $(30.2 \%, 31.7 \%$, $53.8 \%$ respectively $\mathrm{P}<0.01$ ). Sanjuan et al [42] studied 253 patients and demonstrated a significant reduction of AF from $22 \%$ to $10 \%$ comparing atenolol with sotalol. Janssen et al [43], randomized 130 patients to sotalol, metoprolol or no therapy. Only $2.4 \%$ of patients receiving sotalol went into AF, compared with $15 \%$ in the metoprolol group and 36\% of controls, which was a significant finding. Parikka et al [44] randomised 191 patients to receive either sotalol or metoprolol. Postoperative AF observed in only $16 \%$ of patients receiving sotalol compared with $32 \%$ of those receiving metoprolol ( $\mathrm{p}<0.01)$. Nystrom et al [45], randomised 101 patients to high dose sotalol or $(1 / 2)$ dose b-blockers. Postoperative AF occurred in $10 \%$ of patients in sotalol group compared with $29 \%$ in the b-blocker group, revealing a statistical significant diferrence $(\mathrm{p}=0.028)$. Abdulrahman et al [46], randomized 191 patients to sotalol or metoprolol. The incidence of AF was $10 \%$ in the sotalol group and $22 \%$ in the metoprolol group. Finally, Crystal et al [47], briefly summarized these studies and demonstrated that the incidence of AF in the sotalol groups was $12 \%$ compared with $22 \%$ in the bblocker groups, which was a significant finding. In these studies, either $40 \mathrm{mg}$ tds or $80 \mathrm{mg}$ bd were safe but doses higher than those associated with a higher incidence of side effects. Wunderman et al [48], performed a meta-analysis including 10 randomized trials (1403 patients) comparing sotalol and amiodarone. Incidences of postoperative AF in sotalol group were $21.5 \%$ versus $14.1 \%$ in amiodarone group, presenting no significant difference. Also, the adverse effects that required drug discontinuation as well as the length of hospital stay was similar between two regiments. Sotalol can be proarrhythmic as in non-surgical patients the proarrhythmic risk has been reported to be $4.3-5.9 \%$. Because of the proarrhythmic effects of sotalol, ordinary beta-blockers are a safer alternative to sotalol in the prevention of AF after surgery [2].

\section{Amiodarone}

Amiodarone has been proved to be useful in the prevention of postoperative AF. Mitchel et al, in the PAPABEAR trial randomized 600 patients, who were listed for non-emergent CABG and/or valve replacement/repair surgery, to receive amiodarone or placebo [49]. In amiodarone group $(n=299)$ amiodarone was given orally 10 $\mathrm{mg} / \mathrm{kg} /$ day 6 days prior to surgery through 6 days after the surgery (13 days), whereas placebo was administered for the same period. Remarkably, amiodarone reduced significantly $(\mathrm{p}<0.001)$ postoperative AF incidence (16.1\%) compared to placebo (29.5\%). Also, Daud et al [50], randomized 124 patients underwent elective 
cardiac surgery to receive oral amiodarone $(600 \mathrm{mg} /$ day prior and $200 \mathrm{mg} /$ day after surgery) or placebo for 7 days prior the surgery until the discharge. Similarly, amiodarone presented a statistically significant $(\mathrm{p}=$ $0.03)$ decrease in postoperative AF incidence $(23 \%)$ compared to placebo (42\%). Redle et al, evaluated 150 patients undergoing CABG in a randomized double blind controlled trial, comparing amiodarone with placebo [51]. In amiodarone group, the two grams were given in a graduated dosing schedule and then the patients received $400 \mathrm{mg} /$ day beginning on the first postoperative day and continued for seven days. The incidence of postoperative AF was not affected by the prophylactic oral amiodarone as there was no difference between the two groups $(\mathrm{p}=0.3)$. A serious study limitation was that the contaminant use of digoxin, calcium channel blocker and $\beta$-blocker was not controlled.

The duration and dosage of amiodarone has also been evaluated. Especially, Giri et al, in AFIST I trial divided randomly 220 patients over 60 years of age into two groups: amiodarone and placebo [52]. Amiodarone was given orally beginning either the first postoperative day at dosage of 6 gr over 6 days or the 5th preoperative day at dosage of $7 \mathrm{gr}$ over 10 days. The incidence of postoperative AF was reduced in amiodarone (28\%) group compared to placebo (38\%) but without revealing any significant difference $(\mathrm{p}=0.01)$. White et al [53], in AFIST II, trial randomized 160 patients underwent cardiothoracic surgery to amiodarone or placebo and then to pacing or no pacing using a $2 \times 2$ fractional design. All therapies began within 6 hrs post surgery. Amiodarone was given by intravenous infusion for the first $24 \mathrm{hrs}$ (1050 mg total) followed by oral therapy (400 mg three times daily) for 4 postoperative days ( $4800 \mathrm{mg}$ total). Atrial septal pacing was given for 96 hrs. Amiodarone reduced the risk of AF by $43 \%$ and the risk of symptomatic AF by $68 \%(\mathrm{p}=0.037$ and $\mathrm{p}=0.019)$ versus placebo. Atrial septal pacing did not reduce AF or symptomatic AF incidence compared to no pacing. Notably, the risk of postoperative AF in patients receiving amiodarone and pacing was lower than the placebo/ no pacing and the placebo/pacing groups $(57.9 \%$ and $60.5 \%$ reductions, $\mathrm{p}=0.047$ and $\mathrm{p}=0.040$ respectively).

The effect of intravenous amiodarone therapy has also been investigated. Guarnieri et al [54], in ARCH trial randomized 300 patients underwent open heart surgery to amiodarone infusion or placebo. The drug infusion was started within 3 hours of entering the surgical ICU amiodarone was infused at rate of 1 gr over 24 hrs for 2 days (2 g total). Postoperative atrial fibrillation occurred $35 \%$ in amiodarone group versus $47 \%$ in placebo, revealing no statistically significant difference $(\mathrm{p}=0.01)$.

Similarly, Yagdi et al [55], randomized 157 patients to amiodarone infusion or placebo. Amiodarone infusion without a loading dose was given at a dose of $10 \mathrm{mg} / \mathrm{kg} /$ day within 2 hours of entering the cardiovascular ICU for 48 hours. On 2 nd postoperative oral amiodarone was initiated at $600 \mathrm{mg} /$ day three times daily for 5 days, $400 \mathrm{mg}$ per day twice daily for the following 5 days, and $200 \mathrm{mg}$ per day in a single dose for the last 20 days. Amiodarone did not reduce significantly postoperative AF incidence compared to placebo (19, $4 \%$ vs $25 \%)$. Kerstein et al [56], randomized 143 patients that were scheduled for CABG to amiodarone infusion or placebo. IV amiodarone, $0.73 \mathrm{mg} / \mathrm{min}$, without any loading dose was administered on call to the operating room for 48 $\mathrm{h}$, and followed by oral amiodarone, $400 \mathrm{mg} \mathrm{q} 12 \mathrm{~h}$, for the next 3 days. Atrial fibrillation occurred in 3 of 51 patients $(5.88 \%)$ in the amiodarone group, compared to 24 of 92 patients $(26.08 \%)$ in the control group, presenting no statistical significant difference. Of note, most patients also received b-blockers and this study is limited by its non-randomised design. Also, Lee et al [57], began i.v. amiodarone 3 days before CABG and continued it for 5 days after surgery. The incidence of AF was lower and the duration shorter in the amiodarone group than in the placebo group ( $12 \%$ vs. $34 \%)$, respectively. Doerge et al [58], randomized 150 patients into amiodarone or placebo groups. Amiodarone given IV for 3 days following surgery did not decrease the incidence of AF. Treggiari-Venzi et al [59], conducted a randomized controlled double-blind trial in which patients received amiodarone postoperatively ( $900 \mathrm{~g} /$ days for $72 \mathrm{~h}$ ) and demonstrated that the decrease in AF was not statistically significant.

The efficacy of amiodarone has also been compared with other agents such as b-blockers, sotalol, digoxin and diltiazem. Especially, Tokmakoglu et al [60], allocated randomly 241 patients, undergoing elective CABG into three groups. Patients in first group (i) received metoprolol $100 \mathrm{mg} / 24 \mathrm{~h}$ per oral preoperatively, $2 \times 0.5$ $\mathrm{mg}$ digoxin intravenously in the early postoperative period and $0.25 \mathrm{mg}$ digoxin in combination with $100 \mathrm{mg}$ metoprolol per os on the first postoperative day until discharge. Patients in second group (ii) received totally $1200 \mathrm{mg} \mathrm{IV} / 24 \mathrm{hrs}$ amiodarone which the $300 \mathrm{mg}$ bolus dose/ 1 hour was given as soon as the operation had been finished. On the next day patients were given $450 \mathrm{mg} / 24 \mathrm{~h}$ amiodarone IV and then $600 \mathrm{mg} /$ day in three doses per os until discharge. Third group was the control group with no prophylaxis. AF occurred in $16.8 \%, 8,3 \%$ and $33.6 \%$ of patients in group i, ii and iii respectively. Both study groups were significantly effective in the prevention of post-CABG AF with respect to control group $(\mathrm{p}<0.01$ in group $\mathrm{i}$ and $\mathrm{p}<0.001$ in group ii versus control). Sleilaty et al [61], randomized 200 , admitted for elective CABG to receive oral amiodarone or oral bisoprolol beggining $6 \mathrm{hrs}$ after surgery. 
Amiodarone patients received $15 \mathrm{mg} / \mathrm{kg}$, followed by 7 $\mathrm{mg} / \mathrm{kg} / \mathrm{d}$ until discharge and then $200 \mathrm{mg} / \mathrm{d}$ for one month. The patients in bisoprolol group received $2.5 \mathrm{mg}$ then $2.5 \mathrm{mg}$ bid bisoprolol indefinitely in the postoperative period. Postoperative AF occurred in $15.3 \%$ of the patients in the amiodarone group and $12.7 \%$ of the patients in the bisoprolol group showing no significant difference concerning the onset time of AF episode, total duration and recurrence of AF. On the contrary, Solomon et al [62] performed a randomized study on 102 consecutive patients undergoing cardiovascular surgery. The patients were randomized to receive amiodarone $(1 \mathrm{gr} /$ day intravenously for $48 \mathrm{hrs}$, then $400 \mathrm{mg} /$ day orally until discharge) or propranolol (1 mg intravenously every $6 \mathrm{hrs}$ for $48 \mathrm{hrs}$, then $20 \mathrm{mg}$ orally four times a day until discharge). The incidence of postoperative AF was significantly lower in amiodarone group (16\%) compared to propranolol treated patients $(32.7 \%, \mathrm{p}=0.05)$, showing the superiority of amiodarone. Mooss et al, in REDUCE trial evaluated 160 patients underwent CABG, combined CABG and AVR surgery, or AVR surgery alone [63]. Patients were randomized to receive either sotalol $80 \mathrm{mg}$ twice daily or intravenous amiodarone $15 \mathrm{mg} / \mathrm{kg}$ over $24 \mathrm{hrs}$ followed by oral amiodarone $200 \mathrm{mg}$ three times daily. Postoperative $\mathrm{AF}$ occurred in $17 \%$ of patients randomized to amiodarone and in $25 \%$ of those randomized to sotalol, revealing no significant difference $(\mathrm{p}=0.21)$ and further similar efficacy between two regiments. On the other side, Mikroulis et al, randomized 120 patients underwent CABG to receive amiodarone (300 $\mathrm{mg}$ IV, followed by $1 \mathrm{gr}$ IV daily for $48 \mathrm{hrs}$, then $400 \mathrm{mg}$ IV daily for further $48 \mathrm{hrs}$ ) or diltiazem(continuous infusion/minimum dose $0.1 \mathrm{mg} / \mathrm{kg} / \mathrm{h}$ ) followed by an oral b-blocker for the remainder of their hospitalization [64]. The incidence of post-CABG AF was not significantly different between amiodarone (11.7\%) and diltiazem (10\%).

Finally, meta-analyses concerning prophylactic effect of amiodarone in prevention of postoperative cardiac surgery have also been performed. Particularly, Bagshaw et al, performed a meta-analysis included 19 randomized control trials (3295 patients) of amiodarone [65]. Amiodarone significantly reduced the odds ratio of AF ( $\mathrm{p}<$ $0.0001)$, ventricular tachyarrhythmias $(p<0.0001)$, strokes $(\mathrm{p}=0.02)$ as well as duration of hospitalization ( $\mathrm{p}<0.0001)$. Also, Haan et al [66], evaluated 7 randomized control trials including 1064 patients. They concluded that amiodarone decreased the incidence of postoperative $\mathrm{AF}$ in all of the studies, and reached statistical significance in two $[57,66]$. Patel A et al [67], analyzed 18 randomized controlled trials enrolling 3408 patients so as to assess the safety of amiodarone in prevention of postoperative AF. Notably, they showed that amiodarone is associated with an increased risk of developing bradycardia and hypotension especially when average daily dose of IV amiodarone exceeds 1 gr. Finally, Crystal et al [47], summarized ten randomized controlled trials and reported an incidence of AF of $22.5 \%$ in the amiodarone groups and an incidence of $37 \%$ in control groups.

\section{Magnesium}

Low magnesium concentrations are independent risk factors of AF after cardiovascular surgery. Several studies have been conducted using magnesium as prophylaxis agent postoperatively.

Kohno et al, evaluated 200 patients who underwent isolated initial CABG operation in a not randomized retrospective study [68]. The first 100 patient did not receive prophylactic treatment, whereas the next 100 patients were treated with $10 \mathrm{mmol}$ of magnesium sulfate infused IV daily for 3 days after surgery. The incidence of post-operative atrial fibrillation was $35 \%$ in the untreated group compared with $16 \%$ in the magnesium group ( $\mathrm{p}=0.002)$. An important limitation is the lack of randomization and the nature of retrospective analysis that have weakened the cogency of the study.

Kaplan et al [69], conducted a randomized study on 200 consecutive patients in whom they performed initial elective CABG. In treatment group 100 patients received $3 \mathrm{~g}$ magnesium intravenously preoperatively, perioperatively and for the 3 following postoperative days. No significant difference was found compared to the control group, although in a sub-analysis of patients who had low pre-operative serum magnesium, a significant reduction $(\mathrm{p}<0.05)$ in AF was demonstrated. Yeatman et al [70], performed the largest study on magnesium prophylaxis. Especially, 400 patients were randomized in a double blind fashion to receive $40 \mathrm{mmol}$ of $2 \mathrm{mmol} / \mathrm{ml}$ magnesium sulphate in the cardioplegia solution or controls. The incidence of AF was $22 \%$ in the magnesium group compared with $29 \%$ in controls, which was nonsignificant, although the findings were significant in a subset analysis of urgent patients. However, authors acknowledged that they should have used a higher dose of magnesium to obtain a concentration nearer to 15 $\mathrm{mmol} / \mathrm{l}$ of cardioplegia, as their dose only produced a concentration of $5 \mathrm{mmol} / \mathrm{l}$. Similarly, Zangrillo et al [71], randomized 160 consecutive patients underwent elective isolated, off-pump CABG to receive either 2.5 gr magnesium sulphate infusion intraoperatevely over 30 minutes or normal saline solution. Postoperative atrial fibrillation occurred in $20 \%$ of patients treated with magnesium and in $22.5 \%$ of patients in placebo group ( $\mathrm{p}$ $=0.9$ ), revealing no statistical difference between the two groups. On the contrary, Toraman et al, performed an randomized contolled study in 200 patients, giving them either $6 \mathrm{mmol}$ of magnesium both pre-operatively 
and post-operatively or placebo [72]. Only $2 \%$ of patients receiving magnesium went into AF compared with $21 \%$ in the control group. Unfortunately, patients receiving b-blockers or digoxin were excluded. Also, Hazelrigg et al, randomized 105 patients to receive 80 $\mathrm{mg} / \mathrm{kg}$ of magnesium pre-operatively, then $8 \mathrm{mg} /(\mathrm{kg} \mathrm{h})$ post-operatively for $48 \mathrm{~h}$ or placebo in 97 patients [73]. Thirty two patients treated with magnesium went into AF compared with 41 control patients, which was a non-significant trend towards benefit. However, the reduction in AF was significantly different between groups on day 1. Fanning et al, performed a randomized study in which patients received either magnesium 178 $\mathrm{mEq}$ or placebo for 4 days following surgery, showing that the incidence of AF was lower in the magnesium group [74]. Moreover, Maslow et al, conducted a retrospective study included patients undergoing beating heart CABG and demonstrated that magnesium treated patients were less likely to experience postoperative AF than other patients (12\% vs. $29 \%)$ [75]. On the other hand, Wistbacka et al [76], performed a double-blind study so as to assess the dosage of magnesium in the prevention of AF. Of note, the highest dose of magnesium ( $4.2 \mathrm{~g}$ before surgery, $11.9 \mathrm{~g}$ infusion the first postoperative day and $5.5 \mathrm{~g}$ the following day) decreased the incidence of AF more than lower doses $(4.2 \mathrm{~g}, 2.9 \mathrm{~g}, 1.4$ g). Jensen et al instead found that magnesium decreased the duration of AF and flutter, but did not decrease the incidence of AF [77].

In the meantime, there are also negative studies about the preventive effect of magnesium. Particularly, Parikka et al, performed a study in which $70 \mathrm{mmol}$ of magnesium was given in the first $48 \mathrm{~h}$ after surgery [78]. No effect on the incidence of AF was seen, while a high serum magnesium level increased the incidence of AF. In a study of Karmy-Jones et al [79], 14.4 g of magnesium was given during the first $24 \mathrm{~h}$ postoperatively but no effect of magnesium on the incidence of supraventricular tachycardia was shown.

Magnesium has also combined or compared with other agents such as sotalol. Aerra et al, evaluated 103 consecutive coronary patients that received sotalol and magnesium or placebo [80]. These patients received 40 $\mathrm{mg}$ of sotalol orally twice daily from the first postoperative day for 6 weeks and $2 \mathrm{~g}$ of magnesium intravenously immediately post surgery and on the first postoperative day. The incidence of atrial fibrillation in the sotalol and magnesium group was $13.5 \%$ compared to $27.0 \%$ in the controls $(\mathrm{p}=0.025)$. However, the study had serious limitations: retrospective, not randomized and under one surgeon's care. In addition, Forlani et al [81], performed a randomized controlled trial, separating 207 patients into four groups. Patients received either sotalol $80 \mathrm{mg}$ bd or magnesium $1.5 \mathrm{~g}$ orally for 6 days postoperatively or both or neither treatment. Remarkably, only 1 of 52 patients who received both treatments went into AF compared with 19 of 50 control patients. In contrast, Bert et al [82], performed a multi-arm study in 387 patients randomized into six groups of prophylaxis: control, magnesium only, digoxin only, magnesium and digoxin, propranolol only, and magnesium and propranolol. Patients randomized to a regimen including magnesium received $12 \mathrm{~g}$ given during 96 hours postoperatively. Unfortunately, addition of magnesium had no beneficial effect as compared with b-blockers, digoxin or controls.

Several meta-analyses concerning magnesium have also been published. Shiga et al [83], performed a metaanalysis included 17 randomized control trials (2069 patients) summarising papers that contained magnesium alone as prophylaxis and compared it to placebo treatment. Magnesium supplementation reduced significantly the risk of supraventricular arrhythmias $(\mathrm{p}=0.002)$ after cardiac surgery by $23 \%$, of AF by $29 \%$ and of ventricular arrhythmias by $48 \%(\mathrm{p}<0.0001)$. However, magnesium had no notable effect on length of hospitalization, incidence of myocardial infarction or mortality. They also summarised the complications reported in 648 patients. They found no episodes of bradycardia or hypotension. Of note, important differences were found between all these studies and no one prophylactic regime was found to be superior to another. Regimes ranged from a single dose of $5 \mathrm{mmol}$ in the cardioplegia solution to 110 mmol over the course of 3 days. Miller et al, performed a meta-analysis included 20 randomized trials with 2490 patients [84]. They showed that postoperative AF was reduced from $28 \%$ in the control group to $18 \%$ in the treatment group with significant heterogeneity between the trials. Also, magnesium did not significantly reduce hospitalisation duration or mortality. Again, they did not recommend one specific magnesium prophylactic regimen. Finally, the most recent meta-analysis by Alghamdi et al [85], summarized only eight randomized controlled trials that compared magnesium with placebo. They also found a highly significant reduction in relative risk with the addition of magnesium.

\section{Other pharmacological prevention}

Nonsteroidal anti-inflammatory medications have also been tested as prophylaxis of post-CABG AF. Cheruku et al [86], randomized 100 patients to receive either ketorolac $30 \mathrm{mg}$ IV/6 hour followed by ibuprophen 600 mg p.o. three times daily for 7 days or no drugs. Of note, postoperative AF was reduced from $28.6 \%$ (control group) to $9.8 \%$ in the ibuprophen group ( $\mathrm{p}=0.017$ ). Two randomized controlled trials have also been conducted concerning the effect of corticosteroids. Especially, Halonen et al [87], evaluated 241 consecutive 
patients, underwent first CABG and/or aortic valve replacement in a double-blind multicenter trial. Patients were randomized to receive either $100 \mathrm{mg}$ hydrocortisone or placebo. The incidence of postoperative AF was significantly lower in hydrocortisone group $(30 \%)$ compared to placebo $(48 \%, \mathrm{p}=0.004)$. Also, Prasongsukarn et al [88], randomized 86 patients underwent elective first time CABG to $1 \mathrm{gr}$ of methylprednisolone IV before surgery and $4 \mathrm{mg}$ of dexamethasone IV every 6 hours for 1 day after surgery or placebo. Postoperative AF was significantly lower in steroid group (21\%) compared to placebo group (51\%, p = 0.003). However, patients in steroid group presented more complications and further prolonged hospitalization. Also, the effect of antioxidant agent $\mathrm{N}$-acetylcysteine (NAC) has been evaluated in postoperative AF. Ozaydin et al [89], conducted a prospective; double-blind trial consisted of 115 patients undergoing $C A B G$ and/or valve surgery that randomized to NAC or placebo. The incidence of postoperative AF was lower in NAC (5.2\%) compared to placebo $(21.1 \%, \mathrm{p}=0.019)$ but the mean postoperative hospital stay was similar in both groups $(\mathrm{p}=0.82)$. Bothe et al [90], evaluated 11 randomized trials (468 patients) referring to the effect of glucose-insulin-potassium therapy (GIK) after cardiac surgery. Particularly, the findings indicate that GIK may considerably improve postoperative recovery of contractile function and further reduce the incidence of postoperative AF. Finally, ARMYDA-3 a randomized, prospective, doubleblind, placebo-controlled trial evaluated the effect of atorvastatin in reducing postoperative $\mathrm{AF}$ in 200 patients undergoing elective cardiac surgery [91]. Treatment with atorvastatin $40 \mathrm{mg} /$ day initiated one week before surgery, significantly reduced the incidence of postoperative AF versus placebo ( $35 \%$ vs $57 \%$, p = $0.003)$. On the contrary, Virani et al [92], conducted a retrospective cohort analysis consisted of 4044 patients underwent cardiac surgery without a history of chronic or paroxysmal AF that dived into two groups: those who received preoperative statin therapy and those who did not. They demonstrated that preoperative statin therapy was not associated with decreased incidence of postoperative AF including patients with severe left ventricular dysfunction.

\section{Conclusions}

In conclusion, b-blockers should routinely be used as first choice for the prophylaxis of AF in all patients undergoing cardiac surgery, unless otherwise contraindicated (Grade A recommendation based on level 1a studies) [3]. Sotalol may be more effective than standard bblockers for the prevention of AF without causing an excess of side effects (Grade A recommendation based on level 1b studies). Amiodarone should be used for prophylaxis of AF in all patients undergoing cardiac surgery in which b-blocker therapy is not possible (Grade A recommendation based on level 1a and1b studies). In high-risk patients receiving b-blocker therapy for prophylaxis of AF, amiodarone may also be used as additional prophylaxis with an acceptably low incidence of complications [3]. These patients should be protected from the complications of bradycardia with temporary pacing wires being placed intra-operatively (Grade A recommendation based on level $1 \mathrm{~b}$ studies) [3].

\section{Authors' contributions}

All authors: 1. have made substantial contributions to conception and design, or acquisition of data, or analysis and interpretation of data; 2. have been involved in drafting the manuscript or revisiting it critically for important intellectual content; 3 . have given final approval of the version to be published.

\section{Competing interests}

The authors declare that they have no competing interests.

Received: 20 August 2010 Accepted: 30 November 2010 Published: 30 November 2010

\section{References}

1. Shrivastava R, Smith B, Caskey D, Reddy P: Atrial Fibrillation After Cardiac Surgery: Does Prophylactic Therapy Decrease Adverse Outcomes Associated With Atrial Fibrillation. J Intensive Care Med 2009, 24(18), originally published online Nov 17, 2008.

2. Hakala T, Halonen J, Mäkinen K, Hartikainen J: Prevention of atrial fibrillation after cardiac surgery. Scandinavian Cardiovascular Journal 2007, 41:72-78.

3. Dunning J, Treasure T, Versteegh M, Nashef S, EACTS Audit and Guidelines Committee: Guidelines on the prevention and management of de novo atrial fibrillation after cardiac and thoracic surgery. European Journal of Cardio-thoracic Surgery 2006, 30:852-872.

4. Hogue C, Creswell L, Gutterman D, Fleisher L: Epidemiology, Mechanics, and Risks. CHEST 2005, 128:9S-16S.

5. Cleveland J, Grover F: Prophylaxis against atrial fibrillation following open heart surgery. In Advanced therapy in Cardiac Surgery. 2 edition. Edited by: Franco K, Verrier E. BC. Becker; 2003:22-26.

6. Mathew J, Fontes M, Tudor I, Ramsay J, Duke P, Mazer C, Barash P, Hsu P, Mangano D: A multicenter risk index for atrial fibrillation after cardiac surgery. JAMA 2004, 291(14):1720-1729.

7. Ak K, Akgun S, Tecimer T, Isbir CS, Civelek A, Tekeli A, Arsan S, Cobanoglu A: Determination of histopathologic risk factors for postoperative atrial fibrillation in cardiac surgery. Ann Thorac Surg 2005, 79:1970-1975.

8. Jonassen A, Sack M, Mjos O: Yellon. Myocardial protection by insulin at perfusion requires early administration and is mediated via Akt and p70s6 Kinase cell-survival signalling. Circulation research 2001, 89:1191.

9. Hammermeister KE, Morrison D: Coronary bypass surgery for stable angina and unstable angina pectoris. Cardiol Clin 1991, 135-55.

10. Hayashida N, Shojima T, Yokokura Y, Hoei H, Yoshikawa K, Tomoeda H, Aoyag S: P-wave signal-aneraged electrocardiogram for predicting atrial arrhythmia after cardiac surgery. Ann Thorac Surg 2005, 79:859-864.

11. Fleming GA, Marray KT, Yu C, Burbe JG, Petracek MR, Moff SJ, Ball SK, Brown NJ, Pretorius M: Milrinone use is associated with postoperative atrial fibrillation after cardiac surgery. Circulation 2008, 118(16):1619-25.

12. Smith PK, Buhrman WC, Levett JM, Ferguson TB, Holman WL, Cox JL: Supraventricular conduction abnormalities following cardiac operation. J Thorac Cardiovascular Surg 1987, 94:558-565.

13. Rao V, Ivanov J, Weisel RD, Ikonomidis JS, Christakis GT, David TE: Predictors of low cardiac output syndrome after coronary artery bypass. J Thorac Cardiovasc Surg 1996, 122:38-51.

14. Creswell LL, Schuessler RB, Rosenblomm M, Cox JL: Hazards of postoperative atrial arrhythmia. Ann Thorac Surg 1993, 36:253-261. 
15. Zacharias A, Schwan T, Riordan C, Durham S, Shah A, Habib R: Obesity and risk of new-onset atrial fibrillation after cardiac surgery. Circulation 2005, 112:3247-3255.

16. Edgerton J, Herbert M, Prince S, Horswell J, Michelon L, Mangee M, Dewey T, Edgerton Z, Mack M: Reduced atrial fibrillation in patients immediately extubated after off-pump coronary artery bypass grafting. Ann thorac Surg 2006, 81:2121-2127.

17. Chandy J, Nakai T, Lee RJ, Bellow WH, Dzankic S, Leung JM: Increased in Pwave dispersion predict postoperative atrial fibrillation after coronary artery bypass graft surgery. Anest Analg 2004, 98(2):303-10.

18. Hall Rl, Smith MS, Rocker G: The systemic inflammatory response to cardiopulmonary bypass: pathophysiological, therapeutic, and pharmacological considerations. Anest Analg 2007, 85:766-782.

19. Bruins $P$, Te Velthuis $H$, Yazdanbakhsh AP, Jansen P, Van Hardevelt FWJ, De Beaumonte MFH, Wilddevuur CRH, Eijsman L, Trouwbosta A, Hack CE: Activation of the complement system during and after cardiopulmonary bypass surgery: postsurgery activation involves $\mathrm{C}$-reactive protein an dis associated with postoperative arrhythmia. Circulation 1997, 96:3542-3558.

20. Lamm G, Auer J, Weber T, Berent R, Eber B: Postoperative white blood cell count predicts atrial fibrillation after cardiac surgery. I Cardiothorac Vasc Anesth 2006, 20:51-56.

21. Ishida K, Kimura F, Imamaki M, Ishida A, Shimura H, Kohno H, Sakurai M, Miyazaki M: Relation of inflammtory cytokines to atrial fibrillation after off-pump coronary artery by-pass grafting. Eur J Cardiothorac Surg 2006, 29:501-505.

22. Andrews TC, Reimold SC, Berlin JA, Antman EM: Prevention of supraventricular arrhythmias after coronary artery bypass surgery. A metaanalysis of randomised control trials. Circulation 1991, 84:III236-44.

23. Crystal E, Connolly SJ, Sleik K, Ginger TJ, Yusuf S: Interventions on prevention of postoperative atrial fibrillation in patients undergoing heart surgery: a meta-analysis. Circulation 2002, 106:75-80.

24. Ferguson Jr, Coombs LP, Peterson ED: Society of Thoracic Surgeons National Adult Cardiac Surgery Database. Pre-operative B-blocker use and mortality and morbidity following CABG surgery in North America. J Am Med Assoc 2002, 287:2221-7, S.J.

25. Connolly SJ, Cybulsky I, Lamy A, Roberts RS, O'brien B, Carroll S, Crystal E, Thorpe KE, Gent M: Beta-Blocker Length of Stay (BLOS) study. Doubleblind, placebo controlled, randomized trial of prophylactic metoprolol for reduction of hospital stay after heart surgery: the beta-blocker length of stay (BLOS) trial. Am Heart J 2003, 145:226-232.

26. Lucio EA, Flores A, Blacher C, Leyes PE, Lucchese FA, Ribeiro JP. Effectiveness of Metoprolol in Preventing Atrial Fibrillation and Flutter in the Postoperative Period of Coronary Artery Bypass Graft Surgery. Arq Bras Cardiol 2003, 82(1):42-6.

27. Tsuboi J, Kawazoe K, Izumoto H, Okabayashi H: Postoperative Treatment With Carvedilol, a-Adrenergic Blocker, Prevents Paroxysmal Atrial Fibrillation After Coronary Artery Bypass Grafting. Circ J 2008, 72:588-591.

28. White HD, Antman EM, Glynn MA, Collins JJ, Cohn LH, Shemin RL, Friedman PL: Efficacy and safety of timolol for prevention of supraventricular tachyarrhythmia after coronary artery bypass surgery. Circulation 1984, 70:479-484.

29. Lamb RK, Prabhakar G, Thorpe JAC, Smith S, Norton R, Dyde JA: The use of atenolol in the prevention of supraventricular arrhythmias following coronary artery surgery. European Heart Journal 1988, 9:32-36.

30. Halonen J, Hakala T, Auvinen T, Karjalainen J, Turpeinen A, Uusaro A, Halonen P, Hartikainen J, Hippelaeinen M: Intravenous administration of metoprolol is moer effective than oral administration in the prevention of atrial fibrillation after cardiac surgery. Circulation 2006, 114:1-1-1-4.

31. Maniar PB, Harris NB, Tamis JE, Steinberg JS: Intravenous versus oral beta blocker for prevention of post-CABG atrial fibrillattion in high risk patients identified by signal averaged ECG: Lessons of pilott study. Cardiac electrophysiology Review 2003, 7:158-161.

32. Balcetyte-Harris N, Tamis JE, Homel P, Menchavez E, Steinberg JS: Randomized study of early intravenous esmolol in preventing postCABG atrial fibrillation in high risk patients identified by signal-averaged ECG: Results of a pilot study. Ann Noninvasive Electrocardiol 2002, 7:86-91.

33. Acikel S, Bozbas H, Gultekin B, Aydinalp A, Saritas B, Bal U, Yildirir A, Muderrisoglu H, Sezgin A, Ozin B: Comparison Of efficacy of metoprolol and carvedilol for preventing atrial fibrillation after coronary bypass surgery. International journal of cardiology 2008, 126:108-113.
34. Haghjoo M, Saravi M, Hashemi MJ, Hosseini S, Givtaj N, Ghafarinejad MH, Khamoushi JA, Emkanjoo Z, Fazelifar AF, Alizadeh A, Sadr-Ameli MA: Optimal beta-blocker for prevention of atrial fibrillation after on-pump coronary artery bypass graft surgery: Carvedilol versus metoprolol. Heart Rythm 2007, 4:1170-1174

35. Yazicioglu L, Eryilmaz S, Sirlak M, Inan MB, Aral A, Tasoz R, Akalin H: The effect of preoperative digitalis and atenolol combination on postoperative atrial fibrillation incidence. European Journal of Cardiothoracic Surgery 2002, 22:397-401.

36. Merrick AF, Odom NJ, Keenan DJ, Grotte GJ: Comparison of propafenone to atenolol for the prophylaxis of postcardiotomy supraventricular tachyarrhythmias: a prospective trial. European Journal of Cardio-Thoracic Surgery 1995, I(9):146-149.

37. Pfisterer ME, Kloeter-Weber UCD, Huber M, Osswald MS, Buser PT, Skarvan K, Stulz PM: Prevantion of supraventricular tachycardia after open heart operation by low-dose sotalol: A prospective randomized, double blind, randomized, placebo-controlled trial. Ann Thorac surgery 1997, 64:1113-1119.

38. Gomes AJ, Ip J, Santoni-Rugiu F, Mehta D, Ergine A, Lasman MS, Pe E, Newhouse Takle T, Chao Sally MS, Oral BS: Sotalol reduces the incedence of postoperative atrial fubrillation in coronary artery bypass surgery patients: A randomized, double blind, placebo-controlled study. J Am Coll Cardiol 1999, 34:334-9.

39. Suttorp MJ, Kingma JH, Joe Gin Tijon RM, Van Hemel NM, Koomen EM, Defauw JA, Adan AJ, Ernst SM: Efficacy and safety of low and high dose sotalol versus propranolol in the prevention of supraventricular tachyarrhythmias early after coronary artery bypass operations. J Thorac Cardiovasc Surg 1990, 100:921-6.

40. Suttorp MJ, Kingma JH, Peels HO, Koomen EM, Tijssen JG, Van Hemel NM, Defauw JA, Ernst SM: Effectiveness of sotalol in preventing supraventricular tachyarrhythmias shortly after coronary artery bypass grafting. Am J Cardiol 1991, 68:1163-9.

41. Auer J, Weber T, Berent R, Puschmann R, Hartl P, Choi-Keung Ng, Schwarz C, Lehner E, Strasser U, Lassnig E, Lamm G, Eber B: A comparison between oral antiarrhythmic drugs in the prevention of atrial fibrillation after cardiac surgery: The Pilot Study of Prevention of Postoperative Atrial Fibrillation (SPPAF), a randomized, placebo-controlled trial. Am Heart J 2004, 147:636-43.

42. Sanjuan R, Blasco M, Carbonell N, Jorda A, Nunez J, Martinez-Leon J, Otero E: Preoperative use of sotalol versus atenolol for atrial fibrillation after cardiac surgery. Ann Thorac Surg 2004, 77:838-43.

43. Janssen J, Loomans L, Harink J, Taams M, Brunninkhuis L, Van Der SP, Kootstra G: Prevention and treatment of supraventricular tachycardia shortly after coronary artery bypass grafting: a randomised open trial. Angiology 1986, 37:601-9.

44. Parikka H, Toivonen $L$, Heikkila L, Virtanen $K$, Jarvinen A: Comparison of sotalol and metoprolol in the prevention of atrial fibrillation after coronary artery bypass surgery. J Cardiovasc Pharmacol 1998, 31:67-73.

45. Nystrom U, Edvardsson N, Berggren H, Pizzarelli GP, Radegran K: Oral sotalol reduces the incidence of atrial fibrillation after coronary artery bypass surgery. Thorac Cardiovasc Surg 1993, 4:34-7.

46. Abdulrahman $\mathrm{O}$, Dale HT, Levin $\mathrm{V}$, Hallner $\mathrm{M}$, Theman $\mathrm{T}$, Hassapyannes $\mathrm{C}$ : The comparative value of low dose sotalol vs metoprolol in the prevention of post-operative supraventricular arrythmais. Eur Heart J 1999, 20:372.

47. Crystal E, Connolly SJ, Sleik K, Ginger TJ, Yusuf S: Interventions on prevention of postoperative atrial fibrillation in patients undergoing heart surgery: a meta-analysis. Circulation 2002, 106:75-80.

48. Wunderman RL, Mooss AN, Mohiuddin SM, Lenz TL: Amiodarone vs sotalol as prophylaxis against atrial fibrillation/flutter after heart surgery:a metaanalysis. Chest 2002, 121:1203-10.

49. Mitchell LB, Exner DV, Wyse DG, Mitchell LB, Exner DV, Wyse DG, Connolly CJ, Prystai GD, Bayes AJ, Kidd WT, Kieser T, Burgess JJ, Ferland A, MacAdams CL, Maitland A: Prophylactic Oral Amiodarone for the Prevention of Arrhythmias That Begin Early After Revascularization, Valve Replacement, or Repair. PAPABEAR: A Randomized Controlled Trial. JAMA 2005, 294(24):3093-3100.

50. Daoud EG, Strickberger A, Ching Man, Goyal R, Deeb M, Bolling SF, Pagani FD, Bitar C, Meissner MD, Morady F: Preoperative amiodarone as prophylaxis against atrial fibrillation after heart surgery. $N$ Engj J Med 1997, 337:1785-91 
51. Redle JD, Khurana S, Marzan R, McCullough PA, Stewart JR, Westveer DC, O'Neill WW, Bassett JS, Tepe NA, Frumin HI: Prophylactic oral amiodarone compared with placebo for prevention of atrial fibrillation after coronary artery bypass surgery. Am Heart J 1999, 138:144-50.

52. Giri S, White CM, Dunn AB, Felton $K$, Freeman-Bosco L, Reddy $P$, Tsikouris JP, Wilcox HA, Kluger J: Oral amiodarone for prevention of atrial fibrillation after popen heart surgery, the Atrial Fibrillation Suppression Trial (AFFIST): a randomised placebo-controlled trial. Lancet 2001, 357:830-36.

53. Reddy P, Gallagher R, Jeffrey Kluger, White CM, Caron MF, Kalus JS, Rose H, Song J: Suppression Trial II (AFIST II) Prevent Post-Cardiothoracic Surgery Atrial Fibrillation: The Atrial Fibrillation Intravenous Plus Oral Amiodarone, Atrial Septal Pacing, or Both Strategies. Circulation 2003, 108:II-200-II-206.

54. Guarnieri T, Nolan S, Gottlieb SO, Dudek A, Lowry DR: Intravenous amiodarone for the prevention of atrial fibrillation after open heart surgery: Amiodarone Reduction in Coronary Heart (ARCH) Trial. J Am Coll Cardiol 1999, 34:343-7.

55. Yagdi T, Nalbantgil S, Ayik F, Apaydin A, Islamoglu F, Posacioglu H, Calkavur T, Atay Y, Buket S, Dr Yagdi: Amiodarone reduces the incidence of atrial fibrillation after coronary artery bypass grafting. J Thorac Cardiovasc Surg 2003, 125:1420-1425.

56. Kerstein J, Soodan A, Qamar M, Majid M, Lichstein E, Hollander G, Shani J: Giving IV and oral amiodarone perioperatively for prevention of postoperative atrial fibrillation in patients undergoing coronary artery bypass surgery. Chest 2004, 126:716-724.

57. Lee SH, Chang CM, Lu MJ, Lee RJ, Cheng JJ, Hung CR, Chen SA Intravenous amiodarone for prevention of atrial fibrillation after coronary artery bypass grafting. Ann Thorac Surg 2000, 70:157-61.

58. Doerge H, Schoendube FA, Schoberer M, Stellbrink C, Voss M, Messmer BJ: Intraoperative amiodarone as prophylaxis against atrial fibrillation after coronary operations. Ann Thorac Surg 2000, 69:1358-62.

59. Treggiari-Venzi MM, Waeber JL, Perneger TV, Suter PM, Romand A, Romand J: Intravenous amiodarone or magnesium sulphate is not costbeneficial prophylaxis for atrial fibrillation after coronary artery bypass surgery. Br J Anaesth 2000, 85:690-5.

60. Tokmakoglu H, Kandemir O, Gunaydin S, Catav Z, Organcioglu C, Zorlutuna Y: Amiodarone versus digoxin and metoprolol combination for then prevention of postcoronary bypass atrial fibrillation. European Journal of Cardio-thoracic Surgery 2002, 21:401-405.

61. Sleilaty G, Madi-Jebara S, Yazigi A, Haddad F, Hayeck G, Rassi IE, Ashoush R, Jebara V: Postoperative oral amiodarone versus oral bisoprolol as prophylaxis against atrial fibrillation after coronary artery bypass graft surgery: A prospective randomized trial. International Journal of Cardiology 2008, 137:116-122.

62. Solomon AJ, Greenberg MD, Kilborn MJ, Katz NM, Washington : Amiodarone versus a $\beta$-blocker to prevent atrial fibrillation after cardiovascular surgery. American Heart Journal 2001, 142:811-815.

63. Mooss AN, Wurdeman RL, Sugimoto JT, Packard KA, Hilleman DE, Lenz LT, Rovang KS, Arcidi JM, Mohiuddin SM: Amiodarone versus sotalol for the treatment of atrial fibrillation after open heart surgery: The Reduction in Postoperative Cardiovascular Arrhythmic Events (REDUCE) trial. American Heart Journal 2004, 148(4):641-8.

64. Mikroulis D, Didilis V, Konstantinou F, Tsakiridis K, Vretzakis G, Bougioukas G: Diltiazem versus Amiodarone to Prevent Atrial Fibrillation in Coronary Surgery. Asian Cardiovasc Thorac Ann 2005, 13:47-52.

65. Bagshaw SM, Galbraith PD, Mitchell LB, Sauve R, Exner DV, Ghali WA: Prophylactic Amiodarone for Prevention of Atrial Fibrillation After Cardiac Surgery: A Meta-Analysis. Ann Thorac Surg 2006, 82:1927-37.

66. Haan CK, Geraci SA: Role of Amiodarone in Reducing Atrial Fibrillation After Cardiac Surgery in Adults. Thorac Surg 2002, 73:1665-9.

67. Patel AA, White CM, Gillespie EL, Kluger J, Coleman Cl: Safety of amiodarone in prevention of Postoperative atrial fibrillation: a metaanalysis. Am J Health-Syst Pham 2006, 63(9):829-837.

68. Kohno H, Koyanagi T, Kasegawa H, Miyazaki M: Three-Day magnesium administration prevents atrial fibrillation after coronary artery bypass grafting. Ann Thorac Surg 2005, 79:117-26.

69. Kaplan M, Kut Sinan M, Icer Akif U, Demirtas Murat M: Intravenous magnesium sulfate prophylaxis for atrial fibrillation after coronary artery bypass surgery. J Thorac Cardiovasc Surg 2003, 125:344-52.
70. Yeatman M, Caputo M, Narayan P, Lotto AA, Ascione R, Bryan AJ, Angelini GD: Magnesium-supplemented warm blood cardioplegia in patients undergoing coronary artery revascularization. Ann Thorac Surg 2002, 73:112-8.

71. Zangrillo A, Landoni G, Sparicio D, Pappalardo F, Bove T, Cerchierini E, Sottocorna O, Aletti G, Crescenzi G: Perioperative magnesium supplementation to prevent atrial fibrillation after off-pump coronary artery surgery: A randomzed controlled study. Journal of cardiothoracic and vascular anesthesia 2005, 19(6):723-728.

72. Toraman F, Karabulut EH, Alhan HC, Dagdelen S, Tarcan S: Magnesium infusion dramatically decreases the incidence of atrial fibrillation after coronary artery bypass grafting. Ann Thorac Surg 2001, 72:1256-61.

73. Hazelrigg SR, Boley TM, Cetindag IB, Moulton KP, Trammell GL, Polancic JE, Shawgo TS, Quin JA, Verhulst S: The efficacy of supplemental magnesium in reducing atrial fibrillation after coronary artery bypass grafting. Ann Thorac Surg 2004, 77:824-30.

74. Fanning WJ, Thomas CS, Roach A, Tomichek R, Alford WC, Stoney WS: Prophylaxis of atrial fibrillation with magnesium sulphate after coronary artery bypass grafting. Ann Thorac Surg 1991, 52:529-33.

75. Maslow AD, Regan MM, Heindle S, Panzica P, Cohn WE, Johnson RG: Postoperative atrial tachyarrhythmias in patients undergoing coronary artery bypass graft surgery without cardiopulmonary bypass: A role for intraoperative magnesium supplementation. I Cardiothorac Vasc Anesth 2000, 14:524-30.

76. Wistbacka JO, Koistinen J, Karlqvist KE, Lepojarvi MV, Hanhela R, Laurila J, Nissinen J, Pokela R, Salmela E, Ruokonen A: Magnesium substitution in elective coronary artery surgery: A double-blind clinical study. J Cardiothorac Vasc Anaest 1995, 9:140-6.

77. Jensen BM, Alstrup P, Klitgard NA: Magnesium substitution and postoperative arrhythmias in patients undergoing coronary artery bypass grafting. Scand Cardiovasc J 1997, 31:265-9.

78. Parikka H, Toivonen L, Pellinen T, Verkkala K, Järvinen A, Nieminen MS: The influence of intravenous magnesium sulphate on the occurrence of atrial fibrillation after coronary artery bypass operation. Eur Heart J 1993, 14:251-8.

79. Karmy-Jones R, Hamilton A, Dzavik V, Allegreto M, Finegan BA, Koshal A: Magnesium sulfate prophylaxis after cardiac operations. Ann Thorac Surg 1995, 59:502-7.

80. Aerra V, Kuduvalli M, Moloto AN, Srinivasan AK, Grayson AD, Fabri BM, Oo AY: Does prophylactic sotalol and magnnesium decrease the incidence of atrial fibrillation following coronary artery bypass surgery: a propensity-matched analysis. J Cardiothorac Surg 2006, 1:6.

81. Forlani S, De Paulis R, De Notaris S, Nardi P, Tomai F, Proietti I, Ghini AS, Chiariello $L$ : Combination of sotalol and magnesium prevents atrial fibrillation after coronary artery bypass grafting. Ann Thorac Surg 2002, 74:720-5.

82. Bert $A A$, Reinert $S E$, Singh AK: A beta-blocker, not magnesium, is effective prophylaxis for atrial tachyarrhythmias after coronary artery bypass graft surgery. J Cardiothorac Vasc Anesth 2001, 15:204-9.

83. Shiga T, Wajima Z, Inoue T, Ogawa R: Magnesium prophylaxis for arrhythmias after cardiac surgery: a meta-analysis of randomized controlled trials. Am J Med 2004, 117(5):325-33.

84. Miller S, Crystal E, Garfinkle M, Lau C, Lashevsky I, Connolly SJ: Effects of magnesium on atrial fibrillation after cardiac surgery: a meta-analysis. Heart 2005, 91:618-623.

85. Alghamdi AA, Al-Radi OO, Latter DA: Intravenous magnesium for prevention of atrial fibrillation after coronary artery bypass surgery: a systematic review and meta-analysis. J Card Surg 2005, 20:293-9.

86. Cheruku KK, Ghani A, Ahmad F, Pappas P, Silverman PR, Zelinger A, Silver MA: Efficacy of nonsteroidal anti-inflammatory medications for prevention of atrial fibrillation following coronary artery bypass graft surgery. Prev Cardiol 2004, 7(1):13-8.

87. Halonen J, Halonen $\mathrm{P}$, Järvinen $\mathrm{O}$, Taskinen $\mathrm{P}$, Auvinen $\mathrm{T}$, Tarkka $\mathrm{M}$, Hippeläinen M, Juvonen T, Hartikainen J, Hakala T: Corticosteroids for the prevention of atrial fibrillation after cardiac surgery: a randomized controlled trial. JAMA 2007, 297(14):1562-7.

88. Prasongsukarn K, Abel JG, Jamieson WR, Cheung A, Russell JA, Walley KR, Lichtenstein SV: The effects of steroids on the occurrence of postoperative atrial fibrillation after coronary artery bypass grafting surgery: a prospective randomized trial. J Thorac Cardiovasc Surg 2005, 130(1):93-8. 
89. Ozaydin M, Peker O, Erdogan D, Kapan S, Turker Y, Varol E, Ozguner F, Dogan A, Ibrisim E: N-acetylcysteine for the prevention of postoperative atrial fibrillation: a prospective, randomized, placebo-controlled pilot study. Eur Heart J 2008, 29(5):625-31.

90. Bothe W, Olschewski M, Beyersdorf F, Doenst T: Glucose-insulin-potassium in cardiac surgery: a meta-analysis. Ann Thorac Surg 2004, 78(5):1650-7.

91. Patti G, Chello M, Candura D, Pasceri V, D'Ambrosio A, Covino E, Di

Sciascio G: Randomized trial of atorvastatin for reduction of postoperative atrial fibrillation in patients undergoing cardiac surgery: results of the ARMYDA-3 (Atorvastatin for Reduction of MYocardial Dysrhythmia After cardiac surgery) study. Circulation 2006, 114(14):1455-61

92. Virani SS, Nambi V, Razavi M, Lee W, Elayda M, Wilson JM, Ballantyne CM: Preoperative statin therapy is not associated with a decrease in the incidence of postoperative atrial fibrillation in patients undergoing cardiac surgery. Am Heart J 2008, 155:541-6.

doi:10.1186/1749-8090-5-121

Cite this article as: Koniari et al:: Pharmacologic prophylaxis for atrial fibrillation following cardiac surgery: a systematic review. Journal of Cardiothoracic Surgery 2010 5:121.

\section{Submit your next manuscript to BioMed Central and take full advantage of:}

- Convenient online submission

- Thorough peer review

- No space constraints or color figure charges

- Immediate publication on acceptance

- Inclusion in PubMed, CAS, Scopus and Google Scholar

- Research which is freely available for redistribution

Submit your manuscript at www.biomedcentral.com/submit 